Pathophysiology

of Haemostasis and Thrombosis
Pathophysiol Haemost Thromb 2005;34:71-79

DOI: $\underline{10.1159 / 000089928}$

\title{
Demonstration of a Threshold Response in a Proteolytic Feedback System: Control of the Autoactivation of Factor XII
}

\author{
Jolyon Jesty ${ }^{a}$ José Rodriguez ${ }^{a, b}$ Edward Beltrami ${ }^{c}$ \\ ${ }^{a}$ Division of Hematology, Department of Medicine, State University of New York, Stony Brook, N.Y., \\ ${ }^{b}$ Strang Laboratory of Cancer Research, Rockefeller University, New York, N.Y., and ${ }^{\mathrm{c}}$ Department of Applied \\ Mathematics and Statistics, State University of New York, Stony Brook, N.Y., USA
}

\section{Key Words}

Threshold · Feedback · Protease - Inhibitor · Autolytic • Factor XII

\begin{abstract}
Mathematical analysis of positive feedback loops in proteolytic systems has previously suggested that when the active enzymes are subject to inhibitory control these systems will exhibit threshold behavior. This is demonstrated in the present study, for the autolytic activation of factor XII in the presence of a contact activator and an irreversible inhibitor of factor XIla. The threshold between the two system states - complete factor XII activation, or complete stability - is dependent on the kinetic balance between the catalytic rate of autoactivation and rate of enzyme (factor Xlla) inhibition. Activation of the system can be brought about by either increasing the catalytic rate (in this study, by using more potent contactactivation conditions), or by lowering the enzyme inhibition rate. Previous mathematical work predicted complete stability in a positive-feedback system that is below threshold, and this has been experimentally confirmed.
\end{abstract}

Copyright $(2) 2005$ S. Karger AG, Basel

\section{KARGER}

Fax +4161306 1234

E-Mail karger@karger.ch

www.karger.com
(C) 2005 S. Karger AG, Basel

Accessible online at: www.karger.com/pht

\section{Introduction}

Many of the body's defensive and homeostatic systems involve cascades of proteolytic enzymes. Among the wellstudied examples are complement, which leads to the destruction of cells carrying foreign antigens and to inflammation; blood coagulation, which generates fibrin at a site of vascular damage; various systems that depend on plasmin generation, such as fibrinolysis and cell migration; and apoptosis. Several others also exist.

While these systems depend on the generation of numerous proteases, in the majority of cases the initiating event is the secretion or production not of an active protease, but of an as-yet-inactive zymogen species. Before we consider those that follow this mechanism, let us consider two significant exceptions. The archetype is the cascade activation of trypsinogen and chymotrypsinogen in the gut, which is initiated by the action of enterokinase on trypsinogen, and enterokinase is apparently secreted as an active enzyme [1]. Another exception involves tissue plasminogen activator (tPA), where the secreted single-chain 'zymogen', at least when in the presence of fibrin, itself possesses some significant proteolytic activity [2].

Despite these exceptions, the initial steps of several other systems involve feedback loops, in which a later 
protease or proteases are responsible for generating the initial active enzyme. While a positive feedback loop in isolation is not particularly significant, studies of simplified theoretical models strongly suggest that when in addition there is inhibitory controlof the feedbackenzyme(s), the result will be threshold behavior, where below a certain threshold condition the system will not fire [3]. In this situation the key question is not so much the actual rates at which enzymes are generated or inhibited, but the kinetic balance of generation and inhibition, which controls whether the system fires (above the threshold) or does not (below the threshold). Let us consider some examples of systems that are likely candidates for threshold behavior.

The activation of complement by the $\mathrm{C} 1$ complex (C1q-C1r-C1s), when bound to an activating molecule such as an immune complex, involves the proteolytic activation of two zymogens: $\mathrm{C} 1 \mathrm{r}$ and $\mathrm{C} 1 \mathrm{~s}$. The $\mathrm{C} 1 \mathrm{r}$ zymogen is activated first, in an autolytic feedback $[4,5]$. The protease produced, $\mathrm{C} 1 \mathrm{r}$, then goes on to activate the $\mathrm{C} 1 \mathrm{~s}$ zymogen, generating the enzyme $\mathrm{C} 1 \mathrm{~s}$, which continues the sequence through $\mathrm{C} 2, \mathrm{C} 3, \mathrm{C} 4$, and so forth. Various mechanisms have been proposed to explain the initial activation of $\mathrm{C} 1 \mathrm{r}$, including mechanisms dependent on the zymogen's having proteolytic activity [6], but common to all is some sort of autolytic activation. Although the $\mathrm{C} 1 \mathrm{r}$ zymogen may have proteolytic activity, there appears to be no evidence that rules out the possibility of autocatalysis, in which autoactivation can be initiated by an idling trace of $\mathrm{Clr}$. Key to this hypothesis would be that the binding of $\mathrm{Clq}$ to an activator (e.g., an immune complex) causes an increase in the catalytic activity of $\mathrm{C} 1 \mathrm{r}$ on its zymogen; in other words that bound $\mathrm{C} 1 \mathrm{q}$ acts as a cofactor for the activation of $\mathrm{C} 1 \mathrm{r}$ by $\mathrm{C} 1 \mathrm{r}$. Or, in terms of our view of feedbacks, C1q, by increasing the catalytic rate of $\mathrm{C} 1 \mathrm{r}$ activation, would take the feedback activation loop above its firing threshold and enable the bulk generation of $\mathrm{C} 1 \mathrm{r}$ and $\mathrm{C} 1 \mathrm{~s}$.

Another system that involves positive feedbacks in its initiation is blood coagulation, and these include autolytic feedbacks. There are two initiation pathways of coagulation: the 'contact' system, in which the initiating event is the activation of factor XII in the presence of an activating anionic surface (or 'contact activator'), such as glass, kaolin, dextran sulfate, etc. and the tissue factor (TF) pathway, in which TF forms a complex with plasma factor VII, which is then activated to form a proteolytically active complex, TF:VIIa. Autolytic activation occurs in both cases: factor XIIa activates factor XII [7], and TF:VIIa activates TF:VII [8,9]. Once again, we would see the cofactor (contact surfaces are cofactors for factor XIIa, and TF is the cofactor for factor VII), through its increasing of a catalytic rate, as enabling the firing of the system.

In fibrinolysis, both of the major plasminogen activators (tPA, and urokinase-type plasminogen activator, UPA) are synthesized as single-chain proteins that are then activated to two-chain proteases in feedbacks. The main activator of both is plasmin $[10,11]$, which is the product of both tPA and UPA action, but at least in the case of chicken uPA there is also evidence for autolytic activation at an earlier stage by the two-chain uPA enzyme [12]. tPA is rather different because the single-chain precursor can generate plasmin without a need for feedback activation [2]. In that case there is no question as to how the system can bootstrap its own activation. Other autocatalytic feedbacks are seen in the initiation of the two major cascades of apoptosis, involving caspase- 8 and -9 , and in both cases autocatalytic activation is regulated by cofactors that are central in controlling the onset of apoptosis, APAF-1 and FADD [13-15].

In these pathways there is thus evidence for an initial autolytic event, in which a product enzyme acts on its zymogen to catalyze its generation. Another important aspect of control is that several of these systems are known to be subject to inactivation by protease inhibitors: $\mathrm{C} 1$ inhibitor, which inhibits the active $\mathrm{C} 1 \mathrm{r}$ and $\mathrm{C} 1$ s proteases of complement activation, is also the major plasma inhibitor of factor XIIa; tissue factor pathway inhibitor and antithrombin III (ATIII), which inactivate TF:VIIa; and plasminogen activator inhibitors, which control both tPA and uPA. The inhibition picture for regulation of activated caspase- 8 and -9 is less clear, but there is good evidence for inhibitory control of caspase- 9 , if not caspase-8 [15].

In addition to these examples of autocatalytic events, there are the longer (nonautolytic) feedbacks seen in coagulation, and in the activation of both UPA and tPA by plasmin. Important examples of long-range feedbacks in clotting include the activation of TF:VII by a product enzyme, factor Xa, and activation of factor VIII by thrombin [for review, see 16].

Although we have proposed that threshold properties will arise when a proteolytic positive feedback loop is subject to irreversible inhibitory control, there has been no direct experimental evidence in support of the hypothesis. Ataullakhanov et al. [17] have published the most convincing evidence for a threshold onset of clotting in plasma over a range of $\mathrm{Ca}^{2+}$ ion concentrations, and van't Veer and Mann [18] have demonstrated nonlinear re- 
sponses in thrombin production under varying inhibitory conditions. In neither case, however, was subthreshold stability demonstrated, and the role of feedback loops was not examined.

The present study was devised to test the proposal in a simple feedback system that is amenable to experiment and analysis. The major requirement for this test system was that the rates of both autoactivation and -inhibition be in a reasonable range for experimental observation. Initial trials were devoted to the factor XII/prekallikrein feedback loop, in which each enzyme activates the other zymogen, and we analyzed such a structure [19]. It quickly became clear, however, that the rates of both reactions are too high for easy experimental control by protease inhibitors. The autoactivation of factor XII, in contrast, is a quite inefficient reaction, and we predicted that the firing threshold for this system should occur at relatively low rates of factor XIIa inhibition. This turned out to be the case.

\section{Materials and Methods}

\section{Materials}

Carbonic anhydrase, lactoperoxidase, bovine serum albumin (BSA, grade V), fatty acid-free, sulfatides, and dextran sulfate $(500,000 \mathrm{Da})$ were products of Sigma Chemical Co., St. Louis, Mo., USA). Aminophenylmethylsulfonylfluoride (APMSF) was a product of Calbiochem, San Diego, Calif., USA. $\mathrm{Na}^{125}$ I (carrier-free in $\mathrm{NaOH}$ ) was from Amersham. Polybrene was from Aldrich Chemical. $D$-Pro- $L$-Phe- $L$-Arg- $p$-nitroanilide (S-2302) was obtained from Chromogenix. Purified human factor XII and factor XIIa were purchased from Enzyme Research Laboratories, South Bend, Ind., USA. To reduce the level of any contaminating factor XIIa, the factor XII was diluted in 4 vol TBS (tris-buffered saline: $100 \mathrm{mmol} / 1 \mathrm{NaCl} / 50 \mathrm{mmol} / 1 \mathrm{Tris} / \mathrm{HCl} \mathrm{pH} 7.5$ ) and then treated with $100 \mu M$ APMSF for $20 \mathrm{~min}$ at $37^{\circ} \mathrm{C}$, followed by dialysis $(2 \times 200 \mathrm{vol})$ against $0.15 \mathrm{~mol} / \mathrm{l} \mathrm{NaCl} / 5 \mathrm{mmol} / \mathrm{l} \mathrm{MES} / \mathrm{NaOH} \mathrm{pH}$ 6.0. Human ATIII was purified as previously described for the bovine protein [20]. This method includes a final anion-exchange chromatography step, which prevents heparin contamination of the final preparation.

\section{Radioiodination of Factor XII and Carbonic Anhydrase}

Factor XII and carbonic anhydrase were separately labeled with $\mathrm{Na}^{125} \mathrm{I}$ by a mild method that uses $\mathrm{H}_{2} \mathrm{O}_{2}$ and lactoperoxidase in solution [21]. The lactoperoxidase itself, which remains (though inactive) in the labeled preparation, amounts to less than $2 \%$ of the total protein. Different batches of factor XII and carbonic anhydrase varied from 0.8 to $1 \times 10^{6} \mathrm{cpm} / \mathrm{pmol}$. The method was as follows: factor XII, $2.75 \mu \mathrm{mol} / 1$, was incubated in a $80-\mu \mathrm{l} \mathrm{vol} \mathrm{of}$ TBS with $2.5 \mu \mathrm{g} / \mathrm{ml}$ of lactoperoxidase, $25 \mu \mathrm{mol} / 1$ of $\mathrm{H}_{2} \mathrm{O}_{2}$, and $0.5 \mathrm{mCi}$ of $\mathrm{Na}^{125} \mathrm{I}$ at room temperature for $15 \mathrm{~min}$ with stirring. $\mathrm{NaN}_{3}, 0.05 \%$, was added to stop the reaction. To minimize the risk of autolytic activation during subsequent processing, APMSF,
$125 \mu \mathrm{mol} / \mathrm{l}$, was then added, followed after $2 \mathrm{~min}$ by $1 \mathrm{mmol} / \mathrm{l}$ benzamidine $\mathrm{HCl}$. Finally, $2 \mathrm{mg} / \mathrm{ml}$ of BSA was added and the reaction mixture was applied to a $2-\mathrm{ml}$ column of Sephadex G-25 equilibrated in TBS. Fractions were collected and the first radioactive peak (300-400 $\mu \mathrm{l})$ was pooled and dialyzed 3 times against $10 \mathrm{ml}$ of MES-buffered saline $(0.15 \mathrm{~mol} / 1 \mathrm{NaCl} / 10 \mathrm{mmol} / 1 \mathrm{MES} / \mathrm{NaOH}$ $\mathrm{pH} 6.0$ ) at $4^{\circ} \mathrm{C}$. The labeled protein was stored at $-80^{\circ} \mathrm{C}$. Carbonic anhydrase was iodinated in the same way, omitting the various inhibitor treatments.

\section{Measurement of ${ }^{125}$ I-Factor XII Activation}

Incubations were set up to contain $100 \mathrm{nmol} / 1$ of unlabeled factor XII, 1-2 nmol/1 ${ }^{125} \mathrm{I}$-factor XII, ${ }^{125} \mathrm{I}$-carbonic anhydrase, varying concentrations of ATIII, and the reaction was then initiated by the addition of varying concentrations of a contact activator (dextran sulfate or sulfatide - see Results). Experiments were performed at $37^{\circ} \mathrm{C}$, in the presence of $0.05 \% \mathrm{NaN}_{3}$ to prevent bacterial growth. The carbonic anhydrase was used as an internal standard, to correct for variations in sample loading and protein recovery during gel electrophoresis. Two samples were taken from each reaction, at $0 \mathrm{~h}$ $(<15 \mathrm{~s})$ and at $18 \mathrm{~h}$, and were added to an equal volume of gel sample mixer (10 mmol/1 EDTA/5\% 2-mercaptoethanol/0.025\% bromophenol blue $/ 15 \%$ glycerol $/ 2 \%$ sodium dodecyl sulfate $/ 80 \mathrm{mmol} / 1$ imidazole/ $\mathrm{HCl} \mathrm{pH} \mathrm{6.4),} \mathrm{and} \mathrm{heated} \mathrm{to} 95-100^{\circ} \mathrm{C}$ for $3 \mathrm{~min}$. Samples $\left(20 \mu\right.$ l, containing approximately $8 \times 10^{4} \mathrm{cpm}^{125}$ I-factor XII) were run on discontinuous polyacrylamide gels in dodecyl sulfate (stacking gel 5\% acrylamide in imidazole/ $\mathrm{HCl} \mathrm{pH} 6.8$; separating gel of $12.5 \%$ acrylamide in tris/ $\mathrm{HCl} \mathrm{pH} 8.5$ ).

After electrophoresis the gels were fixed in 25\% isopropanol $/ 10 \%$ acetic acid, dried, and exposed to Kodak X-omat AR film for 18$24 \mathrm{~h}$. Autoradiograms were used to indicate where the radioactive (factor XII and carbonic anhydrase) bands were on the dried gel. The bands were then located by reference to the autoradiogram, cut out, and counted in a gamma counter.

Each gel lane (sample) yielded two samples ('bands') for determination of radioactive content: (1) factor XII, which disappears upon, and is a measure of, factor XII activation; and (2) the stable internal reference, carbonic anhydrase. For each experimental sample on the gel, the radioactivity of the factor XII gel bands ( $\left.\mathrm{cpm}_{\mathrm{XII}}\right)$ was divided by the radioactivity of carbonic anhydrase $\left(\mathrm{cpm}_{\mathrm{CA}}\right)$ bands to yield a cpm $\mathrm{XII} / \mathrm{cpm}_{\mathrm{CA}}$ ratio.

After $18 \mathrm{~h}$ the reaction was considered complete (see Results). Control incubations in the absence of inhibitor, in which $100 \%$ factor XII activation occurred, were used as positive controls to define the experimental background in the $\mathrm{cpm}_{\mathrm{XII}} / \mathrm{cpm}_{\mathrm{CA}}$ ratio. Zero-time samples were used as negative controls to define the initial $\mathrm{cpm}_{\mathrm{XII}} /$ $\mathrm{cpm}_{\mathrm{CA}}$ ratio that corresponded to no factor XII activation. The actual $\mathrm{cpm}_{\mathrm{XII}} / \mathrm{cpm}_{\mathrm{CA}}$ ratios for experimental samples were then interpolated between the two controls to determine the concentration of factor XII.

\section{Chromogenic Assay of Factor XIIa}

The kinetic parameters of autoactivation of factor XII, and of inhibition by ATIII, were determined by discontinuous chromogenic assay of timed samples. The substrate used was $D$-Pro- $L$-Phe$L$-Arg- $p$-nitroanilide (S-2302), at a concentration of $0.4 \mathrm{mmol} / \mathrm{l}$ in a buffer of $0.3 \mathrm{~mol} / 1 \mathrm{NaCl}$ in $50 \mathrm{mmol} / 1$ tricine/ $\mathrm{HCl} \mathrm{pH} \mathrm{8.3.} \mathrm{Assays}$ were standardized with purified factor XIIa. 


\section{Mathematical Analysis}

\section{Symbols, Units}

As in our previous analyses of feedback loops [3, 19], we simplify the analysis by using $\mathrm{Z}$ to represent the zymogen factor XII, E to represent the enzyme factor XIIa, and D to represent the inactive (or 'dead') enzyme formed by reaction of the $\mathrm{E}$ with an irreversible inhibitor. Thus, the activation of factor XII to XIIa, and the subsequent inhibition, are represented as:

$$
\mathrm{Z} \stackrel{\mu}{\longrightarrow} \mathrm{E} \stackrel{\mathrm{k}}{\longrightarrow} \mathrm{D}
$$

where $\mu$ is an apparent first-order rate constant, equal to $\mathrm{k}_{\text {cat }}[\mathrm{Z}] /$ $\left(\mathrm{K}_{\mathrm{m}}+[\mathrm{Z}]\right)$, and $\mathrm{k}$ is the first-order rate constant for inhibition of $\mathrm{E}$. The differential equation for $\mathrm{E}$ is then

$$
[E]^{\prime}=\mu[E]-k[E] .
$$

If $\mu$ is constant, this can be integrated to yield

$$
[\mathrm{E}]_{\mathrm{t}}=[\mathrm{E}]_{0} \mathrm{e}^{(\mu-\mathrm{k}) \mathrm{t}} .
$$

The condition for $\mu$ remaining essentially constant is met in two situations: (1) in the early stages of initiation of any system, [Z] » $[\mathrm{Z}]_{0}$; and (2) when $[\mathrm{Z}] \gg \mathrm{K}_{\mathrm{m}}, \mu \approx \mathrm{k}_{\mathrm{cat}} / \mathrm{K}_{\mathrm{m}}$. In either case it is clear from Eq. 1 that there is a threshold when $\mu=\mathrm{k}$. If $\mu>\mathrm{k}$, enzyme will be exponentially generated, and this will continue. On the other hand, if $\mu<\mathrm{k}$, the initial enzyme present will decay exponentially, and as long as $[E]_{0} \ll[Z]_{0}$ no significant generation of $E$ will occur. An important prediction of this analysis is that the threshold is independent of the initial concentration of $\mathrm{E}$.

\section{Determination of the Consumption of $Z$}

In order to demonstrate the threshold experimentally, we have examined the total consumption of $\mathrm{Z}$, the prediction being that, except in the immediate vicinity of the threshold, consumption will be either negligible or complete. Mathematically, consumption of $\mathrm{Z}$ can be determined for the case that $\mu$ is a constant, as mentioned above. However, it should be noted that in the case that substantial amounts of zymogen are consumed, the assumption that $\mu$ remains constant is incorrect. Estimates of consumption should therefore be considered approximate. The differential equation for the inhibited enzyme, D, is

$$
[\mathrm{D}]^{\prime}=\mathrm{k}[\mathrm{E}] \text {. }
$$

We also invoke a conservation expression,

$$
[\mathrm{D}]_{¥}=[\mathrm{E}]_{0}+[\mathrm{Z}]_{0}-[\mathrm{E}]_{¥}-[\mathrm{Z}]_{¥} .
$$

Integration of Eq. 3 to $t=¥$, and substitution of Eq. 4 , yields

$$
[\mathrm{E}]_{0}+\left[\mathrm{Z}_{0}\right]-[\mathrm{E}]_{\infty}-[\mathrm{Z}]_{\infty}=\mathrm{k} \int_{0}^{\infty}[\mathrm{E}](\mathrm{s}) \mathrm{ds} .
$$

In addition,

$$
[\mathrm{Z}]^{\prime}=-\mu[\mathrm{E}],
$$

which upon integration gives

$$
[\mathrm{Z}]_{\infty}=[\mathrm{Z}]_{0} \mathrm{e}^{-\mu} \int_{0}^{\infty}[\mathrm{E}](\mathrm{s}) \mathrm{ds} .
$$

We may now combine Eq. 5 and 6 to obtain an expression that relates $[\mathrm{Z}]_{¥}$ to the initial conditions and kinetic parameters. Since

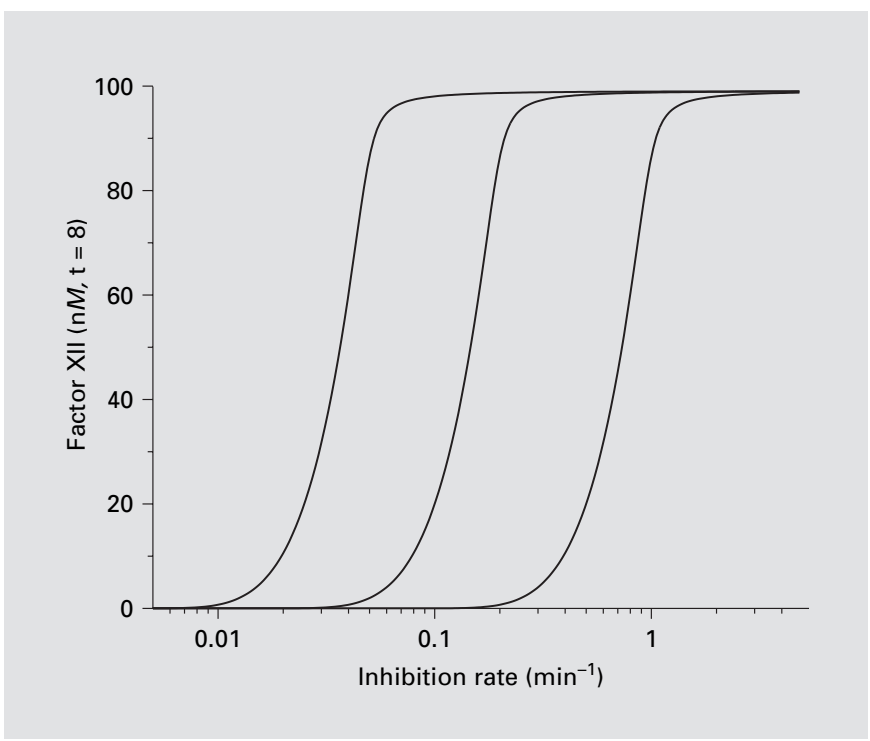

Fig. 1. Predicted stability threshold of an autolytic feedback activation loop as a function of inhibition of the feedback enzyme. Predicted factor XII concentrations remaining at infinite time, $[\mathrm{XII}]_{¥}$, were determined by the solution of Eq. 7 for the following conditions: $[\mathrm{XII}]_{0}=99 \mathrm{n} M ;[\text { XIIa }]_{0}=1 \mathrm{n} M ; \mu$ (left to right $)=0.05,0.2$, and $1 \mathrm{~min}^{-1}$. The threshold for each condition occurs when $\mu=\mathrm{k}$ (inhibition rate).

$[E]_{\sharp}=0$ for all cases where $\mathrm{k}>0$, it may be omitted from Eq. 5, and we obtain

$$
[\mathrm{Z}]_{¥}=[\mathrm{Z}]_{0} \mathrm{e}^{-\mu\left([\mathrm{E}]_{0}+[\mathrm{Z}]_{0}-[\mathrm{Z}]_{y}\right) / \mathrm{k}}
$$

This can be solved for $[\mathrm{Z}]_{¥}$ as a function of $[\mathrm{E}]_{0},[\mathrm{Z}]_{0}, \mu$, and $\mathrm{k}$ using a root-finding routine. To relate this function to experimental results, we may arbitrarily define the experimental threshold as the condition that results in $50 \%$ conversion of $Z$, i.e., $[Z]_{¥}=[Z]_{0} / 2$. This analysis, therefore, predicts that at the threshold $\mu=-2 \mathrm{k}$. $\ln (0.5) \approx 1.4 \times \mathrm{k}$.

The form of this function (Eq. 7), showing the dependence of zymogen activation on the catalytic activation rates $(\mu)$ and inhibition rates $(\mathrm{k})$, is shown in figure 1 . It must be emphasized that this is the predicted extent of zymogen activation at 'infinite time', and confirms the analysis of equations 1 and 2, that at sufficiently high inhibition rates, the zymogen will remain stable. It may also be noted that the function is not symmetrical about the inflexion point, and is not a simple saturating hyperbola.

\section{Results}

\section{Radiolabeled Factor XII as an Indicator of Factor XII Activation \\ Studies of factor XII activation in the presence of fac-} tor XIIa inhibitors require measurement of factor XII activation by methods that do not involve the enzymat- 
Fig. 2. Long-term stabilization of factor XII by inhibition of factor XIIa. Radiolabeled factor XII ( $1 \mathrm{n} M^{125} \mathrm{I}$-factor XII + $100 \mathrm{n} M$ unlabeled factor XII + $1 \mathrm{n} M^{125}$ I-labeled carbonic anhydrase; CA) was incubated in the presence of $1 \mu \mathrm{g} / \mathrm{ml}$ dextran sulfate, plus no inhibitor (left), or $10 \mu M$ ATIII (right). Samples were taken for SDSPAGE at the times shown (hours). The gel was dried and exposed to X-ray film. ${ }^{125}$ I-labeled CA was used in later experiments as an internal standard for the quantification of FXII consumption (see Materials and Methods).

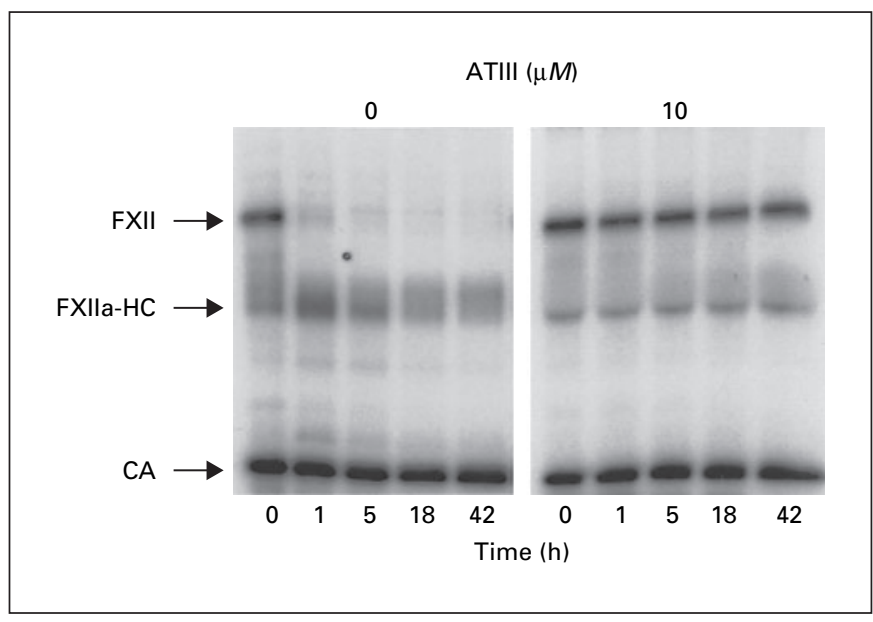

Fig. 3. Experimental demonstration of threshold. Radiolabeled factor XII (1 $\mathrm{n} M$ ${ }^{125}$ I-factor XII + $100 \mathrm{n} M$ unlabeled factor XII) was incubated in the presence of $1 \mu \mathrm{g} /$ $\mathrm{ml}$ sulfatide and increasing concentrations of ATIII. At each ATIII concentration two samples were taken, at 0 and $18 \mathrm{~h}$, and were subjected to gel electrophoresis and autoradiography.

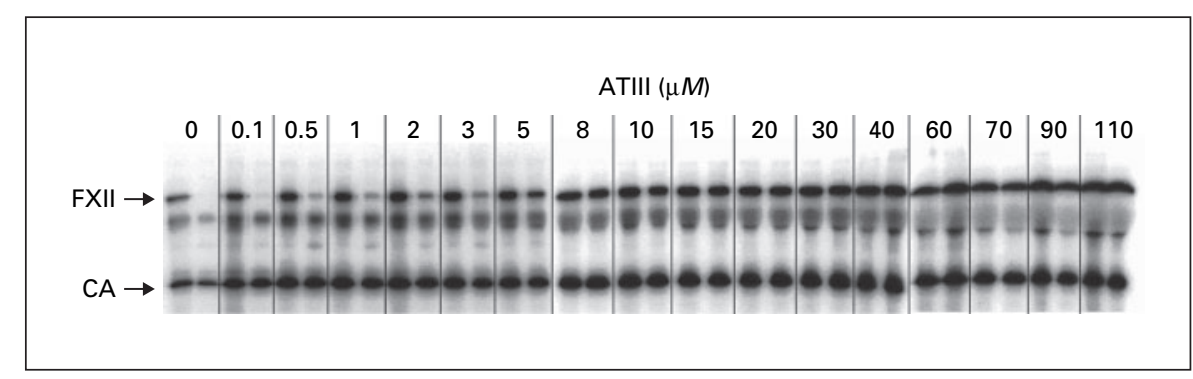

ic activity of factor XIIa. We measured the disappearance of factor XII, using a gel electrophoresis method. Figure 2 shows very long time courses of factor XII activation in the presence of 0 and $10 \mu \mathrm{mol} / \mathrm{l}$ ATIII and $1 \mu \mathrm{g} / \mathrm{ml}$ dextran sulfate. In the absence of inhibitor, factor XII is completely activated in less than $15 \mathrm{~min}$, while at $10 \mu \mathrm{mol} / 1 \mathrm{ATIII}$ it is still stable at $42 \mathrm{~h}$. Time courses showed no significant change from 18 to $42 \mathrm{~h}$, and thus subsequent experiments were considered to be complete after $18 \mathrm{~h}$.

The autoradiograms of figures 2 and 3 show that some preparations of labeled factor XII have minor degradation. To ensure that the radiolabeled factor XII band (arrows) was correctly reporting the activation of the bulk, unlabeled protein, autoactivation experiments in the absence of inhibitor were done to compare the rate and extent of generation of factor XIIa activity, measured by chromogenic assay (discussed in the following section, fig. 5), with the disappearance of ${ }^{125}$ I-factor XII measured as described. The two methods agreed to within $15 \%$ (data not shown).

Factor XII Feedback Activation Threshold

\section{Choice of an Irreversible Inhibitor}

In order to test the prediction of system stability, it was essential that inhibition of factor XIIa be irreversible, since significant equilibrium levels of free enzyme would eventually convert all zymogen to enzyme over the very long time courses. A number of inhibitors were examined. Aprotinin was found to have no inhibitory activity against factor XIIa, and inactivation by $\alpha_{1}$-protease inhibitor was extremely slow. The trypsin inhibitor of maize (corn trypsin inhibitor) is a rapid inhibitor of factor XIIa, but has a relatively weak affinity: from our initial data we estimate an approximate $\mathrm{K}_{\mathrm{d}} \sim 10^{-8} \mathrm{~mol} / \mathrm{l}$. A number of chloromethylketone inhibitors were considered. $D$-Phe- $L$ Phe- $L$-Arg-chloromethylketone and $D$-Phe- $L$-Pro- $L$-Argchloromethylketone both inhibit factor XIIa, but over long time courses at $\mathrm{pH} 7.4$ they are unstable. ATIII was the inhibitor finally used. Although the second-order rate constant for ATIII action on factor XIIa is only $2.5 \mathrm{l} /(\mathrm{mmol} \times \mathrm{min})$, large amounts of ATIII were available. In addition, at the concentrations used (1$100 \mu \mathrm{mol} / \mathrm{l})$, there was no evidence for significant equilibrium levels of factor XIIa, i.e., $\mathrm{K}_{\mathrm{d}}<10^{-9} \mathrm{~mol} / \mathrm{l}$. First- 


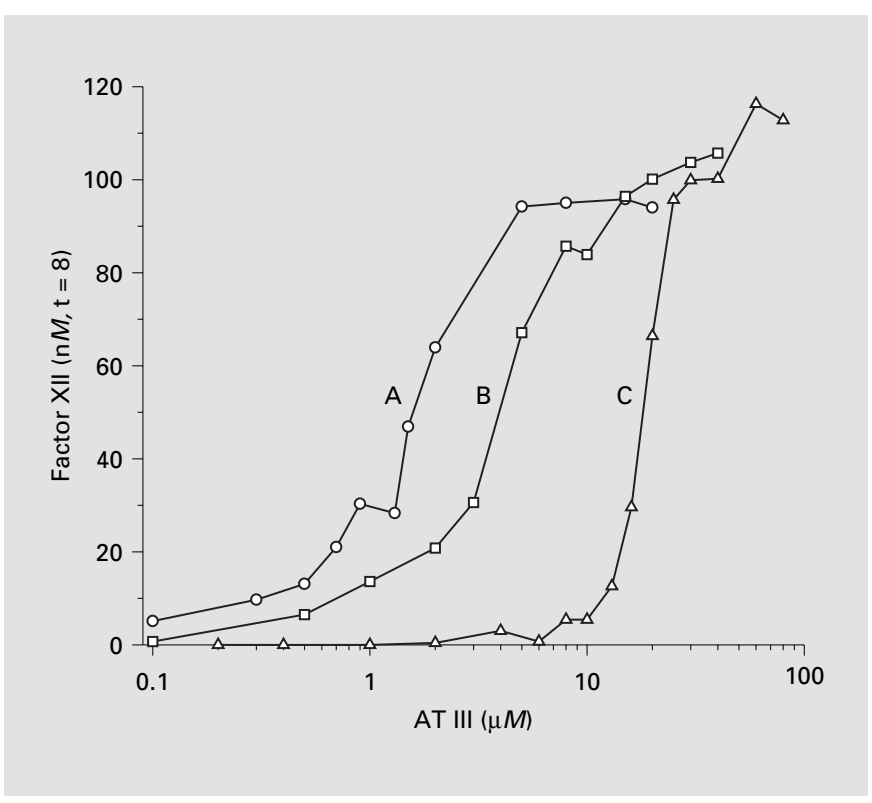

Fig. 4. Stability of factor XII at varying autoactivation rates. Radiolabeled factor XII $(1.2 \mathrm{n} M)$ in the presence of unlabeled factor XII $(100 \mathrm{n} M)$ was incubated for $18 \mathrm{~h}$ in the presence of three contact activators $(0.1$ and $1 \mu \mathrm{g} / \mathrm{ml}$ dextran sulfate, and $5 \mu \mathrm{g} / \mathrm{ml}$ sulfatide) at varying ATIII concentrations (similarly to fig. 3). Factor XII remaining at $18 \mathrm{~h}$ was determined by reference to a zero-time sample and an internal standard of radiolabeled carbonic anhydrase, as described in Materials and Methods.

order rates of factor XIIa inhibition were shown to be proportional to ATIII concentration over this concentration range (data not shown).

\section{Effect of Activation Rate on the Threshold of}

Factor XII Activation in the Presence of ATIII

Figure 3 shows an autoradiogram of a typical large set of reactions with a constant rate of factor XII autoactivation (sulfatide $=1 \mu \mathrm{g} / \mathrm{ml}$ ) in the presence of varying concentrations of ATIII, from 0 to $110 \mu \mathrm{mol} / 1$. At each concentration, samples were taken at 0 and $18 \mathrm{~h}$. The threshold for activation can be clearly seen: at $3 \mu \mathrm{mol} / 1$ ATIII, factor XII is almost totally consumed; whereas at $10 \mu \mathrm{mol} / \mathrm{l}$ ATIII, it is nearly stable. Gels like this were analyzed for factor XII consumption as described in Materials and Methods.

Similar experiments, performed at varying autoactivation rates (by using different conditions of contact activation), and reduced to plots of $[\mathrm{XII}]_{¥}$ against ATIII, are shown in figure 4 . For each, the threshold is clear, the extent of factor XII activation going from complete activa-

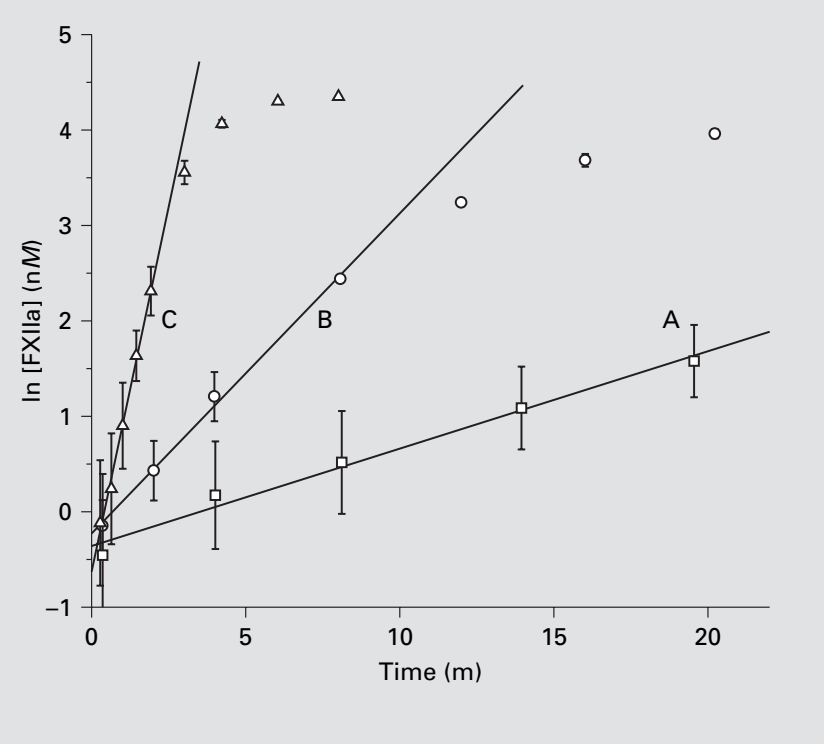

Fig. 5. Autoactivation kinetics of factor XII: determination of $\mu$. Factor XII (100 $\mathrm{n} M)$ was incubated with $5 \mu \mathrm{g} / \mathrm{ml}$ sulfatide (A), $1 \mu \mathrm{g} / \mathrm{ml}$ dextran sulfate (B), and $0.1 \mu \mathrm{g} / \mathrm{ml}$ dextran sulfate (C). Samples were removed at intervals into microplate wells for chromogenic assay of factor XIIa in the presence of Polybrene. The bars show the range of duplicate autoactivation experiments. The lines shown the fit of the first five (A, C) or four (B) data points to a straight line for the determination of $\mu$.

tion at low inhibition rates to complete stability at high inhibition rates. In addition, it is seen that as the autoactivation rate is raised (using a higher dextran sulfate concentration, and then sulfatide), the threshold shifts to the right, i.e., at higher values of $\mu$, proportionately higher inhibition rates $(\mathrm{k})$ are required to block autoactivation.

\section{Effect of the Initial Concentration of Factor XIIa ([E] $\left.]_{0}\right)$}

A prediction from the analysis of feedback loops is that the threshold, being dependent only on $\mu / \mathrm{k}$, should be independent of the level of trace enzyme that is used to initiate the feedback, $[\mathrm{E}]_{0}$. The preparation of factor XII used here was treated with an irreversible inhibitor of trypsin-like enzymes, APMSF, both before and after radiolabeling, and the kinetics of its autoactivation (discussed in the following sections - fig. 5) suggest a level of contamination with factor XIIa activity of approximately $1.6 \%$. Experiments were also performed where the level of factor XIIa was raised to $10 \%$ by the addition of pure enzyme. The results were insufficiently clear to support 
the prediction, the reason being that below the threshold, this initial level of enzyme causes significant transient generation of factor XIIa before autoactivation shuts down. This is not taken into account in the derivation of Eq. 7. Although it was clear that some factor XII remained unactivated at $18 \mathrm{~h}$ in the presence of high concentrations of ATIII, it was significantly less than the near- $100 \%$ recovery observed in the experiments shown in figures 2 and 3.

\section{Kinetic Parameters of Activation}

In order to determine experimental values for the catalytic rate constant, $\mu$, the autolytic activation of factor XII was studied in the presence of dextran sulfate and sulfatide, in the absence of ATIII. Timed samples were removed and the generation of factor XIIa was followed by chromogenic assay. In these experiments Polybrene $(10 \mu \mathrm{g} / \mathrm{ml})$ was added to the chromogenic assay buffer to stop autoactivation at the time of sampling. From Eq. 2, in the absence of any inhibitor, initial generation of enzyme should be described by

$$
\ln [\mathrm{E}]_{\mathrm{t}}=\ln [\mathrm{E}]_{0}+\mu_{0} \mathrm{t}
$$

where $\mu=\mathrm{k}_{\text {cat }}[\mathrm{Z}] /\left(\mathrm{K}_{\mathrm{m}}+[\mathrm{Z}]\right)$. Factor XIIa generation in response to sulfatide $(5 \mu \mathrm{g} / \mathrm{ml})$ and dextran sulfate $(0.1$ and $1 \mu \mathrm{g} / \mathrm{ml}$ ) is shown in figure 5. Exponential generation of enzyme is observed up to about $20 \%$ activation, after which the rate decreases from the pure exponential, presumably due to the reduction in the substrate concentration as activation proceeds. The first four or five data points in each set were fitted to Eq. 8. The slopes, $\mu$, were (A) 1.53 , (B) 0.335 , and (C) $0.102 \mathrm{~min}^{-1}$. The data also permit an estimate of the initial factor XIIa activity in the system, of approximately $1.6 \mathrm{nmol} / 1$, or $1.6 \%$ of the factor XII concentration. Whether this is due to factor XIIa, or perhaps some proteolytic activity of the zymogen itself, is not known.

Because of significant differences in this study between the observed and theoretical threshold 'positions' (see Discussion), we considered the possibility that ATIII, perhaps by binding to the contact activators, might affect the rate of factor XII activation. Autoactivation rates were therefore also measured in the presence of $1 \mu \mathrm{mol} / 1$ ATIII. This concentration is in large mass excess over both the factor XII and contact activators used, but is sufficiently low to have no significant effect on factor XIIa generation and measurement. No differences in the kinetics of enzyme generation were observed.

\section{Kinetic Parameters of Factor XIIa Inhibition}

Factor XIIa was incubated with varying concentrations of ATIII, from 0 to $100 \mu \mathrm{mol} / \mathrm{l}$, and samples were removed for chromogenic assay of the enzyme concentration as a function of time. Pseudo-first-order rate constants were obtained by fitting the data to a single exponential, $[\mathrm{E}]_{\mathrm{t}}=[\mathrm{E}]_{0} \mathrm{e}^{-\mathrm{kt}}$. The first-order rate constants obtained, $\mathrm{k}$, were then plotted against ATIII concentration to obtain the second-order rate constant for inhibition, $2.52 \mathrm{l} /(\mathrm{mmol} \times \mathrm{min})($ data not shown $)$.

Because of the disagreement between threshold prediction and observation alluded to above, the kinetics of factor XIIa inhibition by ATIII were also further studied, and it was shown that the rate constant for inhibition is not significantly affected by either dextran sulfate or sulfatide. Additionally, in order to determine whether some undefined activation product was affecting inhibition, factor XII was allowed to autoactivate in the presence of either dextran sulfate or sulfatide, and the resulting preparation immediately used as the source of factor XIIa for the determination of inhibition kinetics. Again, no significant difference was observed.

\section{Discussion}

The fundamental prediction on which this study was based was that a positive proteolytic feedback loop in which the enzyme(s) are subject to irreversible inactivation should - depending on the initial conditions and kinetic parameters - show two distinct behaviors. When the catalytic rate of enzyme generation exceeds the rate of enzyme inhibition, the system should fire in a manner similar to other excitable systems, and essentially all the zymogen present will be activated. Conversely, if the inhibition rate exceeds the catalytic rate, the system should be stable; and if the inactivation mechanism is irreversible, it should be permanently stable [3].

Two results of this study provide confirmation of these predictions: (1) when inhibition rates are sufficiently high the zymogen, factor XII, remains stable over time courses up to $42 \mathrm{~h}$, (2) as the inhibition rates are lowered, a sharp threshold is observed, and its position is a function of the kinetics of both activation and inhibition.

One prediction, however, has not been confirmed. Theoretical analysis predicts that the threshold should occur when the catalytic rate, $\mu$, equals the inhibition rate, $\mathrm{k}$; but the actual comparisons show a difference of approximately 20 -fold between prediction and observation. However, the system studied is particularly com- 
plex, in that both factor XII and ATIII are known to bind to polysulfated substances like dextran sulfate and sulfatide, and it is possible that one or both rates might be affected by such materials or by each other. While two possible artefactual effects were investigated - a possible direct effect of ATIII on the factor XII autoactivation rate (e.g., a possible interaction of ATIII with the contact-activating material), and an effect of the contact activators on the rate of ATIII inhibition of factor XIIa - the cause of the disparity remains unclear. Nonetheless, the observation of a sharp stability threshold remains.

\section{Stability}

The prediction that the system should be totally stable at sufficiently high inhibition rates is clearly confirmed in figure 2, where factor XII in the presence of $1 \mu \mathrm{g} / \mathrm{ml} \mathrm{dex}$ tran sulfate autoactivates completely in less than $15 \mathrm{~min}$ in the absence of a factor XIIa inhibitor. In contrast, at high factor XIIa inhibition rates the factor XII remains stable for at least $42 \mathrm{~h}$ : a difference in stability of at least 1,000 -fold. The same behavior is observed under different conditions of autoactivation. The extremely long time courses show convincingly that this is not a rate phenomenon but a switch: there is no detectable slow leakage or eventual activation.

The demonstration of stability in an autolytic feedback system is of major significance. If, as we have proposed, the same properties can be demonstrated for more complex, extended loops [3], the result explains how a 'resting' proteolytic system that permanently contains trace levels of initiator and generated enzyme species, like the coagulation system, can nonetheless exist in a stable inactivated state. The key is the balance between the kinetics of enzyme generation and inhibition. If $\mu$ increases or $k$ decreases, the system will pass through a threshold, and stimulation will generate a full response.

\section{Firing Threshold}

Once conditions change so that $\mu>\mathrm{k}$, and as long as there is any finite trace of active factor XIIa present, the system will fire. In terms of the coagulation system, the most common mechanism involves an increase in $\mu$ caused by the appearance of a cofactor. In the case of the contact system, this would be a contact activator. For another autolytic loop that has been well described - the autoactivation of the TF:VII complex - it is the appearance of TF $[8,9]$. In the absence of TF, factor VIIa has no significant activity on factor VII; i.e., $\mu$ is very low. Thus, although factor VIIa is present at idling levels in the plasma, in the absence of TF, the system is stable.

For more complex positive loops, involving more than one step, or even a sequence of such loops, the basic prediction is the same [3]. The remaining major feedbacks in coagulation include (1) the activation of TF:VII by factor $\mathrm{Xa}$, required for factor $\mathrm{X}$ activation by TF:VII(a); (2) the activation of factor VIII by thrombin and factor $\mathrm{Xa}$, in factor $\mathrm{X}$ activation by factor IXa; and (3) the activation of factor $\mathrm{V}$ by thrombin, in the activation of prothrombin by factor Xa. In each a major means of increasing $\mu$ at a site of initiation of hemostasis is the appearance of anionic phospholipid on activated platelets, which raises the catalytic rates by several orders of magnitude. If $\mathrm{k}$ remains essentially unchanged, the result of increasing $\mu$ will be to proportionately lower the threshold stimulus, again by several orders of magnitude. Thus we see how absolute the requirement for activated platelets may be. We propose that it is not just that reactions can only occur very slowly in the absence of anionic phospholipid; it is that they cannot occur at all, because in the absence of appropriate lipid the system is below the feedback threshold.

The present study of a simple autolytic loop shows that the activation threshold does indeed shift as $\mu$ is varied. The analysis also predicts that the threshold should shift in exact proportion to $\mu$ (fig. 1). The three contact-activator conditions used in the later stages of this study gave autoactivation rates $(\mu)$ in the ratio 1 : 0.23:0.07 (fig. 5), and the observed thresholds (fig. 4) are in the ratio $1: 0.2: 0.054$. We consider these ratios to be in excellent agreement.

Of equal physiological significance are threshold shifts that are related to changes in the inhibition rate, $\mathrm{k}$. An example is ATIII, which is the major inhibitor of factor $\mathrm{Xa}$ and thrombin. The rate constants for inhibition of these enzymes increase markedly in the presence of heparin, and this is important with regard to both the presence of heparin-like material on the endothelium, and the situation in heparin anticoagulant therapy. In the present study we could not study the effect of heparin directly, because in addition to its acceleratory effect on ATIII, it can also behave as a contact activator of factor XII [22]. However, we consider it likely from our observations and analysis that the major effect of heparin will be to raise the stimulus threshold of feedback loops that are controlled by ATIII. Thus, if the inhibition rate of a feedback loop enzyme (factor Xa or thrombin) increases 100-fold, we can expect the threshold stimulus for the loop to rise 100-fold. Even more potent, for longer feedback loops that involve two or more enzymes, these effects will mul- 
tiply. In other words, the threshold shifts as the product of the inhibition rates involved [19]. We therefore propose that heparin does not simply damp active coagulant enzymes: it probably also ensures that larger stimuli are required to activate the system.

\section{Acknowledgments}

The authors gratefully acknowledge the very useful discussions of Drs Yale Nemerson and Rodney Gentry in the early stages of this work. The study was supported by National Institutes of Health grant PO1-HL-29019 (JJ).

\section{References}

1 Mann NS, Mann SK: Enterokinase. Proc Soc Exp Biol Med 1994;206:114-118.

-2 Tate KM, Higgins DL, Holmes WE, Winkler ME, Heyneker HL, Vehar GA: Functional role of proteolytic cleavage at arginine-275 of human tissue plasminogen activator as assessed by site-directed mutagenesis. Biochemistry 1987;26:338-343.

3 Beltrami E, Jesty J: Mathematical analysis of activation thresholds in enzyme-catalyzed positive feedbacks: application to the feedbacks of blood coagulation. Proc Natl Acad Sci USA 1995;92:8744-8748.

-4 Dodds AW, Sim RB, Porter RR, Kerr MA: Activation of the first component of human complement $(\mathrm{C} 1)$ by antibody-antigen aggregates. Biochem J 1978;175:383-390.

- 5 Lacroix MB, Aude CA, Arlaud GJ, Colomb MG: Isolation and functional characterization of the proenzyme form of the catalytic domains of human C1r. Biochem J 1989;257:885-891.

-6 Arlaud GJ, Gagnon J, Villers CL, Colomb MG: Molecular characterization of the catalytic domains of human complement serine protease C1r. Biochemistry 1986;25:5177-5182.

7 Dunn JT, Silverberg M, Kaplan AP: Cleavage and formation of activated Hageman factor by autodigestion and by kallikrein. J Biol Chem 1982:257:1779-1784

-8 Nakagaki T, Foster DC, Berkner KL, Kisiel W: Initiation of the extrinsic pathway of blood coagulation: evidence for the tissue factor dependent autoactivation of human coagulation factor VII. Biochemistry 1991;30:10819-10824.
9 Yamamoto M, Nakagaki T, Kisiel W: Tissue factor-dependent autoactivation of human blood coagulation factor VII. J Biol Chem 1992;267:19089-19094.

10 Rijken DC, Hoylaerts M, Collen D: Fibrinolytic properties of one-chain human extrinsic (tissue-type) plasminogen activator. J Biol Chem 1982;257:2920-2925.

11 Zamarron C, Lijnen HR, van Hoef B, Collen D: Biological and thrombolytic properties of proenzyme and active forms of human urokinase. I. Fibrinolytic and fibrinogenolytic properties in human plasma in vitro of urokinases obtained from human urine or by recombinant DNA technology. Thromb Haemost 1984;52: 19-23.

12 Alexander DS, Aimes RT, Quigley JP: What the structure and function of avian plasminogen activator and matrix metalloproteinase-2 reveal about their counterpart mammalian enzymes, their regulation, and their role in tumor invasion. Enzyme Protein 1996;49:38-58.

13 Srinivasula SM, Ahmad M, Fernandes-Alnemri T, Alnemri ES: Autoactivation of procaspase-9 by Apaf-1-mediated oligomerization. Mol Cell 1998;1:949-957.

14 Rodriguez J, Lazebnik Y: Caspase-9 and APAF-1 form an active holoenzyme. Genes Dev 1999;13:3179-3184.
15 Kruidering M, Evan GI: Caspase-8 in apoptosis: the beginning of 'the end'? IUBMB Life 2000; 50:85-90.

16 Jesty J: Blood coagulation: Nature Encyclopedia of Life Sciences. Chichester, Wiley \& Sons, 1999. http://www.els.net/ [doi:10.1038/npg. els.0000904].

-17 Ataullakhanov FI, Pohilko AV, Sinauridze EI, Volkova RI: Calcium threshold in human plasma clotting kinetics. Thromb Res 1994;75: 383-394.

18 van't Veer C, Mann KG: Regulation of tissue factor-initiated thrombin generation by the stoichiometric inhibitors tissue factor pathway inhibitor, antithrombin III, and heparin cofactor II. J Biol Chem 1997:272:4367-4377.

19 Jesty J, Beltrami E, Willems G: Mathematical analysis of a proteolytic positive-feedback loop: dependence of lag time and enzyme yields on the initial conditions and kinetic parameters. Biochemistry 1993;32:6266-6274.

20 Jesty J: The inhibition of activated bovine coagulation factors X and VII by antithrombin III. Arch Biochem Biophys 1978;185:165173

21 Jesty J: Dissociation of complexes and their derivatives formed during inhibition of bovine thrombin and activated factor $\mathrm{X}$ by antithrombin III. J Biol Chem 1979;254:1044-1049.

-22 Silverberg M, Diehl SV: The autoactivation of factor XII (Hageman factor) induced by low$\mathrm{Mr}$ heparin and dextran sulphate. The effect of the $\mathrm{Mr}$ of the activating polyanion. Biochem $\mathrm{J}$ 1987;248:715-720. 